\title{
ANÁLISE ECONÔMICA DO DIREITO APLICADA AO PODER JUDICIÁRIO BRASILEIRO: A FUNÇÃO JUDICANTE COMO "FALHA DE MERCADO"
}

\author{
LAW AND ECONOMICS APPLIED TO THE BRAZILIAN JUDICIARY: THE JUDICIARY \\ FUNCTION AS “MARKET FAILURE”
}

\section{Rafael José Nadim de Lazari}

Advogado e consultor jurídico. Pós-Doutor em Democracia e Direitos Humanos pelo Centro de Direitos Humanos da Faculdade de Direito da Universidade de Coimbra/Portugal. Estágio Pós-Doutoral pelo Centro Universitário

"Eurípides Soares da Rocha”, de Marília/SP. Doutor em Direito Constitucional pela Pontifícia Universidade Católica, de São Paulo/SP. Professor da Graduação, do Mestrado e do Doutorado em Direito da Universidade de Marília/SP - UNIMAR. Coordenador da Pós-Graduação em Direito Constitucional da Rede LFG de Ensino. Professor convidado de Pós-Graduação (LFG, EBRADI, Projuris Estudos Jurídicos, IED, dentre outros), da Escola Superior de Advocacia, e de Cursos preparatórios para concursos e Exame da Ordem dos Advogados do Brasil (LFG, G7, Vipjus, IED, Vocação Concursos, PCI Concursos, dentre outros). Professor dos Programas "Saber Direito" e "Academia", na TV Justiça, em Brasília/DF.

E-mail: prof.rafaeldelazari@hotmail.com

\section{Edson Freitas de Oliveira}

Discente do curso de Doutorado em Direito pela Universidade de Marília/SP - UNIMAR. Mestre em Direito Constitucional pela Instituição Toledo de Ensino - ITE, de Bauru/SP (2001). Graduado em Ciências Contábeis (1987) e Direito (1997) pelo Centro Universitário "Antônio Eufrásio de Toledo", de Presidente Prudente/SP. Advogado e consultor jurídico. Professor Titular de Direito Econômico e Empresarial pelo Centro Universitário "Antônio Eufrásio de Toledo", de Presidente Prudente/SP, bem como Coordenador de Pós-Graduação da mesma Instituição. E-mail: edson_freitas@toledoprudente.edu.br

Recebido em: 26/08/2019

Aprovado em: 20/08/2020

RESUMO: O presente estudo busca demonstrar que a ineficiência do Poder Judiciário brasileiro o transformou no que os juristas adeptos da Análise Econômica do Direito denominam de falha de mercado. O trabalho define, inicialmente, a própria Análise Econômica do Direito, intencionalmente através dos estudos de R. H. Coase, um dos fundadores da escola Law \& Economics, porque mais adequados ao ambiente privado. O estudo está, assim, delimitado na esfera privada, de forma a analisar as soluções que o Direito pode encontrar para as imperfeições de mercado, trazendo para o âmbito jurídico resultados de estudos econômicos. Reconhece-se que as empresas, sempre segundo R. H. Coase, são formas criadas para reduzir custos de transação e que imperfeições de mercado não podem ser solucionadas sem a intervenção do Poder Judiciário (nem pelo próprio mercado, nem pelas empresas), porque os contratos não permitem mais, atualmente, um grau de autonomia suficiente para trazer a solução a todas as falhas de mercado e porque os negócios cada vez mais atingem terceiros, alheios às relações contratuais. Após trazer as definições e aspectos envolvendo as falhas de mercado, o estudo passa a analisar o grau de 
(in)eficiência do Poder Judiciário brasileiro, concluindo que, incapaz de dar solução aos conflitos que poderiam corrigir imperfeições de mercado (especialmente pela morosidade e altos custos) e, portanto, criar ambiente favorável para o desenvolvimento econômico, o próprio Poder Judiciário tornou-se uma falha de mercado. Utilizou-se para desenvolvimento do presente trabalho a pesquisa bibliográfica e a análise histórica. A metodologia utilizada é a hipotético-dedutiva.

Palavras-chave: Análise econômica do direito. Imperfeições de mercado. Custos de transação. Falhas de mercado. Ineficiência do Poder Judiciário.

ABSTRACT: The study seeks to demonstrate that the inefficiency of the brazilian Judiciary has made it what jurists adept at the Law and Economics call market failure. Initially, the paper defines the Law and Economics, intentionally through the studies of R. H. Coase, one of the founders of Law and Economics school, because it is more suited to the environment of private relations. The study is thus delimited in the private sphere, in order to analyze the solutions that the Law can find for market imperfections, bringing to the legal scope results of economic studies. It is recognized that companies, always in the R. H Coase lesson, are ways created to reduce transaction costs and that market imperfections cannot be solved without the intervention of the Judiciary (neither by the market itself, nor by companies), because contracts no longer allow a sufficient degree of autonomy today to bring the solution to all market failures and because businesses are increasingly reaching third parties who are not part of contractual relationships. After bringing the definitions and aspects involving the market failures, the study goes on to analyze the degree of (in) efficiency of the Judiciary function, concluding that, unable to solve the conflicts that could correct market imperfections (especially due to the slowness and high costs) and thus create favorable environment for economic development, the Judiciary itself has become a market failure. It was used for the development of this work the bibliographical research and the historical analysis. The methodology used is hypothetical-deductive.

Keywords: Law and economics. Market imperfections. Transaction costs. Market failures. Inefficiency of the Judiciary.

SUMÁRIO: Introdução; 1. Análise econômica do direito: abordagem necessária dos estudos de R. H. Coase; 2. Falhas de mercado; 3. Judiciário como falha de mercado e o cálculo empresarial; Considerações finais; Referências

\section{INTRODUÇÃO}

O estudo do Direito aliado ao estudo da Economia não é exatamente uma novidade. Muitas são as perspectivas e a análise econômica está presente, atualmente, em todos os ramos do Direito. Desafiou o presente trabalho, entretanto, a tentativa de resposta a uma inquietação: é no campo das Ciências Jurídicas que devem surgir as soluções para as chamadas imperfeições de mercado e essas soluções, para serem eficientes, cada vez mais são decorrentes de análises econômicas. Se os negócios empresariais, que são fundamentais para o desenvolvimento econômico, necessitam das soluções jurídicas para melhorar o ambiente de negociação (para facilitar as transações), o Poder Judiciário deve ser o local onde os empresários encontram o seu ponto de apoio, a sua coluna de sustentação.

Para estruturar os seus negócios os investidores e empresários fazem o planejamento com base nos custos e nos resultados, o que se denominou nesse trabalho de cálculo empresarial. Quando os resultados planejados não ocorrem, há que se buscar no Judiciário a solução correta e célere, de forma a não inviabilizar os negócios. A pergunta é direta: isso vem ocorrendo? 
Para responder a esse questionamento, inicialmente se buscou o estudo das origens da Análise Econômica do Direito, baseado nas lições de R. H Coase. Demonstrou-se que os estudos jurídicos tradicionais, focados em conceitos abstratos e sem levar em consideração os efeitos econômicos das regras jurídicas, não se prestam mais a solucionar os problemas de mercado. Foram trazidas as necessárias definições de imperfeições de mercado, de falhas de mercado e de custos de transação. Verificou-se, utilizando-se como ponto de saída o Teorema de Coase, que somente se justifica a intervenção do Estado nos casos para a solução de falhas de mercado quando não possam ser solucionadas pelo próprio mercado. E, em razão disso, demonstrou-se que o correto funcionamento das instituições jurídicas é importante para o bom funcionamento da economia de mercado.

Passou-se à verificação, então, dos problemas que ocorrem caso haja um mau funcionamento do Judiciário e dos dados disponíveis sobre o funcionamento do Judiciário no Brasil. Constatou-se, como já era esperado, que o país tem sérios problemas com o sistema judiciário, especialmente pela morosidade e pelos altos custos. Os próprios magistrados reconhecem que o Poder Judiciário não tem conseguido atender com eficiência os jurisdicionados. No que diz respeito ao Judiciário ser o ambiente propício para a solução das falhas de mercado, quando não solucionados na esfera privada, chegou-se a uma conclusão assustadora e desastrosa para a economia brasileira: o próprio Judiciário se tornou uma falha de mercado.

Utilizou-se para desenvolvimento do presente trabalho a pesquisa bibliográfica, além da análise histórica. A metodologia utilizada é a hipotético-dedutiva. O ponto de partida, insiste-se, são os estudos de R. H. Coase e a dimensão econômico-jurídica que o autor sempre buscou em sua obra.

\section{ANÁLISE ECONÔMICA DO DIREITO: ABORDAGEM NECESSÁRIA DOS ESTUDOS DE R. H. COASE ${ }^{1}$}

Nos dias atuais, ainda que nem sempre os interlocutores percebam, a repercussão econômica permeia cada vez mais as discussões das ciências jurídicas. Como observam Antonio Carlos Ferreira e Patrícia Cândido Alves Ferreira no estudo introdutório para a edição brasileira da obra de Ronald Harry Coase, "[...] as relações entre o Direito e a Economia não são recentes e têm, ao longo dos tempos, variado de intensidade e importância e, em especial, de percepção por parte dos juristas e economistas" (2016, p. X).

Ainda segundo os mesmos autores, para R. H. Coase, “[...] a maioria dos economistas ignora a firma e o mercado, ainda que ambas as instituições formem a estrutura do sistema econômico [...]" e "[...] para os juristas, a possibilidade de compreender a firma e o mercado representa [...] a oportunidade de se aventurar por uma área promissora do conhecimento" (FERREIRA; FERREIRA, 2016, p. XIII).

$\mathrm{Na}$ verdade, sempre houve uma distância entre juristas, tentando conceituar, classificar e explicar os negócios comerciais (ou empresariais) através de ficções jurídicas (ou conceitos jurídicos), e os economistas, analisando os resultados reais desses negócios, ou, como preferem Ejan Mackaay e Stéphane Rousseau, analisando os efeitos econômicos dos conceitos jurídicos (2015, p. 7). Entre os juristas, conforme lição de Rachel Sztajn, Alberto Asquini definiu que os perfis da empresa são o empresário (perfil subjetivo), o estabelecimento ou azienda (aspecto patrimonial - perfil objetivo), o funcional (que considera empresa como atividade empreendedora, e o institucional (empresário como organizador das pessoas envolvidas) (2010, p. 3).

\footnotetext{
${ }^{1} \mathrm{O}$ presente estudo, de forma proposital, fica restrito ao estudo da AED - Análise Econômica do Direito nas relações privadas (ou aos efeitos sobre elas), mais especificamente no âmbito empresarial. Não se ignora, entretanto, a análise econômica do direito no âmbito do Direito Público, com a constatação, por exemplo, de que direitos e políticas públicas necessitam de recursos para serem assegurados e implementados e que esses recursos são finitos. Nesse contexto, sugere-se a obra de: LAZARI (2012). Também: CALABRESI; BOBBITT (1978).
} 
Todavia, para os economistas, essas ficções, especialmente na escolha dos legisladores italianos (onde surgiu a Teoria da Empresa) e brasileiros (após a edição pelo Código Civil de 2002, que adotou a teria da empresa) ${ }^{2}$, quando elegem o sujeito de direito (empresário) como figura central, levam a enxergar a empresa como criadora de produtos finais (mercados finais), esquecendo-se das etapas da produção, cada vez mais especializadas e relevantes (SZTAJN, 2010, p. 3).

E foi Ronald Harry Coase ${ }^{34}$ quem provocou um grande avanço nas discussões econômicas envolvendo a empresa, passando a estudar a firma (ou a empresa) como instituição econômica ${ }^{5}$. No seu célebre artigo publicado em 1960, sob o título The Problem of social Cost $^{6}$, R. H. Coase esclarece que os empresários, administradores e trabalhadores se reúnem sob a forma de empresa, abandonando a atuação individual para minimizar do que chama de custos de transação.

$\mathrm{O}$ próprio R. H. Coase, passados quase cinquenta anos da publicação do artigo referido no parágrafo anterior, analisando as repercussões da sua obra, concordou com o conceito dado por Carl J. Dahlman aos custos de transação: “[...] custos de busca e informação, custos de barganha e decisão custos de monitoramento e cumprimento". E complementa o raciocínio afirmando que “[...] a existência de custos de transação impulsionará aqueles que desejam realizar trocas a se envolverem em práticas que ocasionam uma redução dos custos de transação sempre que a perda sofrida de outras maneiras pela adoção de tais práticas seja menor dos que os custos de transação economizados" (COASE, 2016, p. 7).

A empresa é vista, então, como uma forma de reduzir os custos das transações caso fossem feitas em contratos individualizados (custos com elaboração de contratos e negociações de acordos, por exemplo). Transferindo a análise para o mercado, R. H. Coase lembra que os mercados são, tradicionalmente, locais destinados a facilitar as trocas (uma feira de negócios é um exemplo) e falham as teorias econômicas que não admitem os próprios mercados como elementos de redução dos custos das transações. Lembra que as bolsas de valores ou de mercadorias são lembradas frequentemente como ambientes que possibilitam perfeita competição, são fortemente reguladas, o que não deveria ocorrer se houvesse mesmo uma concorrência perfeita. Conclui por existir uma falha nessas teorias econômicas: o próprio mercado existe com a finalidade de reduzir os custos de transação (2016, p. 08-11). Um sistema regulado é necessário para reduzir custos e aumentar o volume de negociações.

No que diz respeito à influência do Direito no sistema econômico, R. H. Coase imputa erro ao sistema jurídico quando escolhe assegurar o direito a uma das partes sem avaliar os valores envolvidos no sacrifício econômico de ambos os envolvidos. Entende que "[...] a abordagem tradicional tende a obscurecer a natureza da escolha a ser feita”. E exemplifica (2016, p. 97):

A questão é normalmente pensada como uma situação em que A causa prejuízo a B, e o que precisa ser decidido é: como coibir A? Mas isso está errado. Estamos lidando com um problema de natureza recíproca. Evitar o prejuízo a B seria infligir um prejuízo a A. Desta forma, a verdadeira questão a ser decidida é:

\footnotetext{
${ }^{2}$ Para aprofundamento no assunto: COELHO, 2013, p. 32-45.

${ }^{3}$ Fundador (ou um dos fundadores) da escola Law and Economics, agraciado com Prêmio de Ciências Econômicas em Memória de Alfred Nobel, de 1991. Disponível em: https://www.nobelprize.org/prizes/economicsciences/1991/summary/. Acesso em: 23 mai. 2019.

${ }^{4}$ Destaca-se, também, Guido Calabresi, que, através da publicação de seu artigo Some Thoughts on Risk Distribution and Lew of Torts (Disponível https://digitalcommons.law.yale.edu/cgi/viewcontent.cgi?article=3035\&context=fss_papers. Acesso em: 23 mai. 2019), deu início, juntamente com Ronald H. Coase, ao que posteriormente se denominou Análise Econômica do Direito.

${ }^{5}$ Coase expressamente explica que os seus objetivos são "[...] persuadir meus colegas economistas a modificarem o modo como analisam diversas questões importantes em microeconomia” (2016, prefácio).

${ }^{6}$ Disponível em: https://www.law.uchicago.edu/files/file/coase-problem.pdf. Acesso em: 23 mai. 2019.
} 
deveríamos permitir que A prejudique $\mathrm{B}$ ou deveríamos permitir que $\mathrm{B}$ prejudique A. O problema é evitar o prejuízo mais grave.

Buscando a melhor compreensão do raciocínio, um outro exemplo, também dado pelo autor (2016, p. 97):

Citei como exemplo em um artigo anterior, o caso de um confeiteiro cujas máquinas produziam ruído e vibrações que perturbavam o trabalho de um médico. Poupar o médico de prejuízos seria infligir um prejuízo ao confeiteiro. O problema apresentado neste caso, é essencialmente, se valeria a pena, como resultado da restrição dos métodos de produção que poderiam ser usados pelo confeiteiro, assegurar mais atividades médicas à custa de uma redução na oferta de produtos da confeitaria.

Entretanto, a resposta clara a ser dada somente será possível após o momento em que se sabe o valor do que é obtido e do que é sacrificado. Sem qualquer interferência do Estado (através de legislação ou de acesso ao Judiciário), as partes poderiam encontrar uma solução, tal como, por exemplo, o médico sendo indenizado pelos valores que deixaria de faturar a mais em razão do ruído e das vibrações provocadas pelas máquinas da confeitaria; mas o confeiteiro somente estaria disposto a assim proceder se os valores a pagar ao médico fossem menores do que os necessários para mudar o estabelecimento de local. Outra solução poderia ser o médico pagar ao confeiteiro pela redução da sua produção, igualmente levando em consideração os limites da renda que conseguiria gerar (maiores do que os valores pagos ao confeiteiro).

Quando o Estado é chamado a intervir, contudo, a aplicação da legislação vigente naquele momento ou o julgamento levado a efeito pelo Judiciário não costumam levar essas variáveis econômicas em consideração (COASE, 2016, p. 105-107). Possível admitir, assim, levando-se em consideração apenas os custos privados, uma solução entre os indivíduos na esfera privada, desde que os custos de transação sejam nulos. "Se os direitos de executar certas ações podem ser vendidos ou comprados, eles tenderão a ser adquiridos por aqueles que o consideram mais valiosos" (CONSTANTINO, s.d., s.p.) $)^{7}$.

Nessa linha de raciocínio, determinada atividade poluente, v.g., pode subsistir, desde que pague pela compensação dos prejuízos causados. Considerados os custos sociais (reparação da externalidade negativa) como mensuráveis, estes passam a integrar os custos totais do empreendimento.

Essa discussão levou à criação do chamado Teorema de Coase que, conforme afirmação do próprio R. H. Coase, não foi uma expressão criada por ele (2016, p. 157), mas com base em seus estudos. A publicação que deu origem à discussão foi um artigo publicado no The Journal of Law \& Economics, em outubro de $1959^{8}$, ainda durante a sua graduação, no qual trazia discussões sobre os efeitos dos preceitos das ciências jurídicas quando analisados pela ótica econômica. No referido artigo afirmou (transcrição feita pelo próprio R. H Coase - 2016, p. 157):

Saber se uma caverna recém-descoberta pertence ao indivíduo que a descobriu, ao indivíduo em cujas terras está localizada a entrada da caverna, ou ao indivíduo que possui o terreno sob o qual está situada a caverna depende, sem dúvida, do Direito das Coisas em vigor. O Direito, contudo, determina, apenas com quem é necessário celebrar um contrato para obter uma licença de uso da caverna. Se a caverna será usada para armazenar registros bancários, como reservatório de gás natural ou para o cultivo de cogumelos, depende não do Direito das Coisas, mas

\footnotetext{
7 Disponível em: https://www.gazetadopovo.com.br/rodrigo-constantino/artigos/o-custo-social-a-contribuicao-deronald-coase-aos-estudos-economicos/. Acesso em: 31 mai. 2019.

${ }^{8}$ Disponível em: https://www.journals.uchicago.edu/doi/10.1086/466549?mobileUi=0. Acesso em 24 jun. 2019.
}

Revista de Direito Brasileira | Florianópolis, SC | v. 27 | n. 10 | p.201-215 | Set./Dez. 2020 
de quem vai pagar mais para utilizá-la: o banco, a empresa de gás natural, ou o produtor de cogumelos.

Voltando ao caso do médico e do confeiteiro acima narrado e usando o raciocínio transcrito, tem-se que, independentemente ou não de o confeiteiro ter direito de provocar ruído e vibrações, tal direito seria adquirido pela parte que lhe atribuísse maior valor (tal como ocorreria com a caverna recém-descoberta) e, portanto, “[...] embora a delimitação dos direitos seja um prelúdio essencial para as transações de mercado [...] o resultado final (que maximiza o valor de produção) independe do disposto no ordenamento jurídico" (COASE, 2016, p. 158).

Mas o autor ressalta que esse resultado depende que se assumam custos de transação iguais a zero, pelo que o Teorema de Coase foi redigido por George J. Stigler nos seguintes termos: “[...] sob condições de concorrência perfeita, os custos privado e social serão iguais" (2016, p. 158). Todavia, como as condições de negócios com transação a custo zero são utópicas, e serviram apenas para referencial teórico, há que se levar em consideração os custos de realização das transações de mercado, e "é claro que essa realocação de direitos só ocorrerá se o aumento do valor de produção como consequência do rearranjo for maior do que os custos incorridos para implementá-lo" (2016, p. 115).

Nesse ambiente, a negociação e a apuração dos custos se dão com total liberdade, sem interferência estatal. Assim, pelo Teorema de Coase, segundo Rodrigo Peñaloza:

[...] numa transação econômica com externalidades, se os direitos de propriedade forem bem definidos e se os custos de transação forem suficientemente baixos, então a solução privada é socialmente ótima, não havendo necessidade de intervenção do governo na correção da externalidade, que é uma falha de mercado. O único papel do governo seria assegurar que os direitos de propriedade estivessem bem definidos e que a livre negociação fluísse sem custos de transação (s.d., s.p. ${ }^{9}$ - grifou-se).

Nessa linha de raciocínio, somente se justifica a intervenção do Estado nos casos em que as denominadas falhas de mercado não possam ser solucionadas pelo próprio mercado. É em razão disso que o correto funcionamento das instituições jurídicas é importante para o bom funcionamento da economia de mercado.

\section{FALHAS DE MERCADO}

Mercados são imperfeitos. Segundo Ejan Mackaay e Stéphane Rousseau, “As mais importantes imperfeições de mercado são o monopólio e certas formas de concorrência disfarçadas ou falseadas, os bens coletivos, quer dizer, aqueles que não suscetíveis de apropriação; as externalidades; a informação incompleta ou assimétrica dos participantes em uma operação, ou sua racionalidade limitada" (2015, p. 122 - grifou-se).

$\mathrm{O}$ estudo das externalidades ${ }^{10}$ - ou efeitos externos - decorrentes das atividades empresariais foi justamente, pode-se dizer assim, o ponto de partida para os estudos de R. H Coase,

\footnotetext{
9 Disponível em: https://medium.com/@milesmithrae/externalidades-e-o-teorema-de-coase-rodrigope\%C3\%B1aloza-dez-2015-6ebb29f90120. Acesso em: 31 mai. 2019.

10 "Benefícios obtidos por empresas que se formam (ou já existentes) em decorrência da implantação de um serviço público [...] ou de uma indústria, proporcionando à primeira vantagens antes inexistentes. [...] A existência de economias externas permite em geral uma redução de custos para as empresas e significa uma importante alavanca de desenvolvimento econômico. O contrário acontece quando a instalação de certas atividades traz aumentos de custos para as empresas ou afugenta clientes ou ainda, desestimula a demanda de certos produtos" (SANDRONI, 1999, p. 193).
} 
que passou a tratar os efeitos econômicos dessas externalidades - como custos de transação - de uma forma diferente dos seus antecessores.

Se os custos de transação estão todos sob a gestão de um único proprietário, a questão deve ser vista como custos de administração e a decisão caberá ao proprietário e/ou gestor sobre as vantagens econômicas (maior ou menor rentabilidade) que assunção desses custos trará. O gestor buscará o ótimo de decisão. Todavia, se as propriedades são distintas (custos de transação decorrem de terceiros), esses custos trazidos pelas externalidades podem ser tão altos a ponto de não viabilizar o negócio. Conclui-se que "[...] externalidade é simplesmente o nome que se dá aos custos de interação, ou de coordenação, enquanto os recursos concorrentes estão em diferentes mãos" (MACKAAY; ROUSSEAU, 2015, p. 211).

Ganha fundamental importância, assim, qual a solução jurídica a ser dada para as externalidades uma vez que, lembre-se, na visão de R. H. Coase, firmas são constituídas para reduzir custos de transação. Dependendo da solução jurídica adotada, negócios viáveis podem se tornar inviáveis. É preciso que estejam bem definidas e implementadas as regras jurídicas, razão pela qual "A análise econômica do direito insiste sobre a eficácia de maior parte das normas existentes nos sistemas jurídicos vigentes, e, no plano normativo, sustenta a oportunidade de determinar a solução que seria mais eficaz para questões de política jurídica, quer dizer, de regras futuras" (MACKAAY; ROUSSEAU, 2015, p. 211).

Mas, dado do enfoque do presente trabalho, é necessário voltar-se para a correta definição de falhas de mercado. Importante registrar, de início, que mesmo no âmbito das relações privadas, as partes contratantes raramente gozam de total capacidade de autodeterminação e autorregulação. Com efeito, o contrato com representação de plena autonomia "[...] é visto, atualmente, como a exceção e não mais a regra, tendo de admitir a concepção de que o contrato encontra-se ( $i c$ ) enquadrado na categoria de negócio jurídico a qual 'abrange todas as categorias de ato de autonomia, inclusive aquelas em que não se manifesta a liberdade fática de estabelecer cláusulas"” (TRINDADE, 2013, p. 32-33).

Ainda segundo o mesmo autor, o que se verifica, assim, é que não é possível estabelecer em contratos, na grande maioria das oportunidades, remédios para os desequilíbrios gerados pelos contratos onde existam desequilíbrios entre as partes contratantes. $\mathrm{O}$ mesmo ocorre em razão da forma como os mercados se estruturam, pois, "[...] diante de suas idiossincrasias e peculiaridades circunstanciais, pode facilitar ou mesmo prejudicar que os intercâmbios sejam realizados, bem como aumentar ou diminuir as vantagens obtidas com as transações, inclusive no que tange a terceiros não diretamente envolvidos nas relações contratuais que são realizadas nos âmbitos dos mercados" (TRINDADE, 2013, p. 33).

Como se observa, nos limites da autonomia privada não é mais possível, salvo em cada vez mais raras exceções, antever a solução para as externalidades, seja porque os contratos envolvem partes que não têm absoluta liberdade de contratar, seja porque atingem terceiros não participantes da relação contratual. Fica evidente, então, a importância de o Direito identificar e trazer as soluções para essas situações - cada vez mais frequentes, repita-se - em que ocorrem as falhas de mercado não são solucionáveis pelas próprias partes. E, certamente, nesse momento, a Ciência do Direito deve buscar as soluções mais objetivas e pragmáticas da Ciência Econômica, de forma a aumentar a eficiência dos mercados (TRINDADE, 2013, p. 33).

Conforme Karin Bergit Jakobi e Marica Carla Pereira Ribeiro ensinam, “[...] as noções obtidas por meio do estudo da lógica econômica contribuem para aprimorar o sistema jurídico, por meio da elaboração de lei mais adequadas à realidade, da maior conscientização dos julgadores acerca da repercussão de suas decisões". E acrescentam que "[...] o aperfeiçoamento do sistema jurídico, obtido ao se agregar noções da Economia, tem o poder de acarretar, por conseguinte, um maior desenvolvimento na própria Economia, que passa a contar com o apoio das instituições para organizar o seu funcionamento" (2014, p. 31). 
Pode-se dizer, assim, que as falhas de mercado, segundo Marcelo Vanzella Sartori, “[...] são aquelas que motivam a criação de uma norma de direito econômico. Correspondem a uma situação na qual os mercados reais (de um produto em determinado local) não funcionam tal qual o modelo de mercado idealizara diante de uma maior eficiência econômica" (2009, p. 82).

Por sua vez, Fábio Nusdeo aponta cinco falhas de mercado, que denomina de inoperacionalidades (1995, p. 23):

- a falta de mobilidade de fatores que geras as crises de super ou sub produção;

- o deficiente acesso a todas as informações relevantes pelos agentes econômicos que falseia as suas decisões;

- a concentração empresarial derivada do fenômeno das economias de escala que elimina o jogo concorrencial por inquinar a estrutura mercantil;

- os efeitos externos da atividade econômica produzindo custos e benefícios sociais - as externalidades - que se quedam incompensados e, assim, deixam de sinalizar adequadamente a escassez;

- a impossibilidade de captar as necessidades da comunidade por bens de caráter coletivo, isto é, aqueles que atendem concomitantemente às necessidades de um número razoavelmente grande de pessoas.

Suficientemente definidas e conceituadas as falhas de mercado, nos limites da necessidade do presente estudo, o desafio agora é no sentido de analisar se a própria atuação do Judiciário pode ser considerada uma falha de mercado.

Partindo-se da premissa de que a Ciência Jurídica deve buscar na Ciência Econômica elementos para corrigir as imperfeições do mercado, e que é no campo do Direito que se busca maior eficiência dos mercados, conclusão óbvia é a de que sobre o Poder Judiciário recai a maior parte da responsabilidade desse esperado equilíbrio.

\section{JUDICIÁRIO COMO FALHA DE MERCADO E O CÁLCULO EMPRESARIAL ${ }^{11}$}

Registre-se que o objetivo do presente estudo se restringe à análise do impacto da (in)eficiência do Judiciário no planejamento, execução e resultado final de produtividade e lucratividade das empresas ${ }^{12}$. Por óbvio, uma correta gestão empresarial deve levar em consideração todos os custos envolvidos.

Tratando de planejamento de resultados na gestão empresarial, Fernando Batista Bandeira da Fontoura ressalta que "[...] o resultado é o efeito final de uma complexa relação de visão, planejamento, ações, e operações, que necessita de uma visão holística e detalhada de todos os processos organizacionais [...]” (2013, p. 181). Inquestionável, portanto, ser fundamental para os negócios empresariais fazer valer, via Poder Judiciário, se necessário, o cumprimento da legislação e dos contratos, de forma que componham os resultados de acordo com o planejamento. Por certo, se os resultados dependiam, v.g., do cumprimento de um contrato de compra e venda mercantil inadimplido, há que se obter no Judiciário, em tempo razoável, o cumprimento da obrigação ou a reparação do prejuízo. Da mesma forma, se a legislação previu o dimensionamento de determinadas medidas de compensação por dano ambiental, decorrentes da exploração de uma

\footnotetext{
${ }^{11}$ A expressão "cálculo empresarial" é aqui utilizada para designar, de forma geral, todos os métodos e ferramentas disponíveis que os gestores de empresas se utilizam para planejar os negócios, avaliar os custos e investimentos, auxiliar nas tomadas de decisões e aferir os resultados (produtividade e lucratividade). Em uma abordagem mais técnica do ponto de vista contábil e financeiro, destaca-se o orçamento empresarial. Recomenda-se a obras de Fábio Frezatti (2009) e de Sérgio de Iudícibus (1998).

${ }^{12}$ Não se ignora que a má performance do Poder Judiciário pode provocar grandes prejuízos, também, na esfera pública. São incontáveis, por exemplo, os notórios casos de verdadeiros cerceamentos de direitos fundamentais em razão da demora de prestação jurisdicional ou de outros problemas de gestão dos órgãos jurisdicionais (acesso a direitos básicos, tais como saúde e educação, inclusive).
} 
atividade econômica, o Poder Judiciário tem que corrigir eventuais distorções de interpretação ou coibir tentativas infundadas de impedir a implementação do projeto empresarial.

Se não é possível no âmbito privado, como se demonstrou anteriormente, resolver todas as imperfeições do mercado e se o Direito deve cuidar de resolvê-las para a melhor eficiência dos mercados (com os consequentes ganhos para o desenvolvimento econômico), o Judiciário tem que ser o porto seguro para evitar e/ou corrigir infringências à lei e/ou ao contrato.

Conforme os estudos de R. H. Coase, as empresas são criadas para reduzir os custos de transação. Mas a redução dos custos depende da eficiência da gestão empresarial, e essa, por sua vez, depende de ver observadas e cumpridas as regras levadas em consideração quando do cálculo empresarial. Se a resposta dada pelo Judiciário não for eficiente, acaba se tornando, ele próprio, uma falha de mercado.

Resistindo à tentação de optar pela conclusão fácil, dadas as inúmeras notícias disponíveis sobre problemas com a prestação jurisdicional, há que se verificar pelos estudos feitos sobre o assunto, se realmente o Poder Judiciário brasileiro tem provocado distorções nos resultados das empresas e, consequentemente, no desenvolvimento econômico ${ }^{13} 1415$.

De acordo com Micheli Pereira (que desenvolveu o seu estudo com base em duas pesquisas: a primeira partindo de informações prestadas pelos empresários, feita por Armando Castelar Pinheiro, e a outra a partir de informações prestadas pelos magistrados, feita por Maria Teresa Sadek), partindo-se da concepção dos empresários, "Judiciário que funciona bem é aquele age de forma eficiente, imparcial e pouca custosa, e, via de consequência, o Judiciário que funciona mal é aquele que não atende a estes quesitos" (2010, p. 55).

Já na introdução de seu artigo - localização do problema - Micheli Pereira destaca algumas informações interessantes: i) nem toda morosidade é vista pelos empresários como ruim, porque pode auxiliar no adiamento para o cumprimento de algumas obrigações, beneficiando as suas atividades ${ }^{16}$; ii) os custos processuais não são vistos pelos empresários apenas em razão das custas processuais, honorários advocatícios e periciais, despesas de deslocamento etc., mas, também, pelo desgaste psicológico pelo conflito, pela necessidade de frequentar o ambiente da justiça (expondo sua vida pessoal ao juízo e a terceiros, expor e se expor à verdade e até à mentira, com o gravame de esperar pela demora no processo; iii) quanto à imparcialidade, os empresários reclamam da falta de previsibilidade quanto à possibilidade de calcular as consequências de suas ações, já que na economia as regras do jogo precisam ser claras e estáveis; a insegurança jurídica provocada por essa imprevisão (decorrente da imparcialidade) desestimula o investimento, a produtividade e, via de consequência, o desenvolvimento econômico, porque os investidores tendem a realizar transações econômicas em locais onde haja maior segurança jurídica (2010, p. 54-55).

\footnotetext{
${ }^{13}$ A análise se restringe aos dados e informações organizacionais do Poder Judiciário, deixando de abranger aspectos individuais das decisões judiciais, que podem, certamente, ter alguma interferência nos resultados nas empresas, mas interessam mais a outro campo de estudo. Tayuri Ishi Matsumi e Carmem Letícia de Maia Pereira, por exemplo, desenvolveram estudo sobre Heurísticas e Vieses no Processo Decisório do Juiz (2017, p. 121-139), no qual abordam o processo decisório do juiz sob a ótica de interferências culturais e externas. Os estudos de Pedro Mercado Pacheco (1994, p. 259-284) abordam a necessidade de renovação e atualização de todo o sistema jurídico (inclusive dos magistrados) sobre a AED - Análise Econômica do Direito, apontando como alternativa para a solução da crise da cultura jurídica americana.

${ }^{14}$ Também não se levam em consideração reflexos extrapatrimoniais ou patrimoniais das decisões porque essas, apesar de levarem em consideração a análise econômica do direito e interferirem no resultado patrimonial das empresas, não estão necessariamente relacionadas a falhas do Judiciário. Mas há estudos interessantes sob essa ótica, como o artigo de Fabiano Koff Coulon (2008, p. 175-192), onde se analisam critérios econômicos para quantificação de decisões judiciais indenizatórias.

${ }^{15}$ Da mesma forma é deixada de lado a análise específica sobre a estrutura de gestão dos tribunais. Recomenda-se: SLAIBI FILHO (2016).

16 Todos os estudos mostram que, na verdade, a morosidade é prejudicial para o ambiente empresarial, mas causa espécie o fato de alguns empresários brasileiros terem a coragem de confessar que se beneficiam e até planejam suas atividades contando com essa morosidade.
} 
Citando a pesquisa de Armando Castelar Pinheiro, a autora argumenta que "[...] as decisões judiciais têm uma repercussão econômica, a qual os magistrados deveriam compreender melhor [...] no que toca à imparcialidade das decisões judiciais, (sic) a justiça que os juízes buscam em primeiro momento pode não ser alcançada em um segundo momento, já que os agentes econômicos são regidos, dentre outras coisas, pelos sinais dados e à forma de decidir dos magistrados". Estariam os juízes, assim, colaborando para o aumento do desemprego, da informalidade e da taxa de juros (2010, p. 55-56).

Há, também, uma discussão que ultrapassa o campo dos negócios e que envolve a busca da justiça social. É que, para os empresários, buscar justiça social não é papel do Judiciário, que deve ser obtida através da redistribuição de receitas de impostos e de políticas públicas, devendo o Judiciário manter uma posição neutra, pois caso contrário, estaria prejudicando a economia, desrespeitando contratos, aumentando riscos das transações e introduzindo prêmios de riscos que reduzem salários, aumentam juros, burocracias e preços (PEREIRA, 2010, p. 56).

Certamente, pode-se atribuir a esses posicionamentos dos empresários uma interferência da linha ideológica (discussão sobre o tamanho do Estado) que lhes é mais favorável, mas o fato é que o tema tem trazido preocupações ao Banco Mundial, que editou o Documento Técnico no 319 , através do qual recomendou (DAKOLIAS, s.d., s.p.):

A reforma econômica requer um bom funcionamento do judiciário o qual deve interpretar e aplicar as leis e normas de forma previsível e eficiente. Com a emergência da abertura dos mercados aumenta a necessidade de um sistema jurídico. Com a transição de uma economia familiar - que não se baseava em leis e mecanismos formais para resolução de conflitos - para um aumento nas transações entre atores desconhecidos cria-se a necessidade de maneiras de resolução de conflitos de modo formal. As novas relações comerciais demandam decisões imparciais com a maior participação de instituições formais. Todavia, o atual sistema jurídico é incapaz de satisfazer esta demanda, forçando, consequentemente, as partes a continuar dependendo de mecanismos informais, relações familiares ou laços pessoais para desenvolver os negócios. Algumas vezes isto desestimula as transações comerciais com atores desconhecidos possivelmente mais eficientes gerando uma distribuição ineficiente de recursos. Esta situação adiciona custos e riscos as transações comerciais e assim reduz o tamanho dos mercados, e consequentemente, a competitividade do mercado.

Em outro documento mencionado na obra de Marcelo Roseno Oliveira apud Micheli Pereira (2010, p. 57), o Banco Mundial faz críticas sobre a imprevisibilidade das decisões judiciais e sobre a conduta de proteção a grupos sociais mais frágeis:

As leis substantivas relativas à proteção legal e judicial dos direitos do credor no Brasil não são muito diferentes daquelas encontradas em outros países de direito civil francês e geralmente são consideradas adequadas pelos credores. Entretanto, os procedimentos legislativos são retardados, com recurso a sucessivas apelações e liminares, o que diminui o valor da proteção legal. Além disso, as decisões judiciais sobre questões de crédito são percebidas como sendo pró-devedor, refletindo o ativismo social judicial, às vezes desconsiderando o que está previsto na lei ou no contrato. Consequentemente, a jurisprudência e os padrões de comportamento judicial desempenham um papel tão ou mais importante que a própria lei na regulamentação das questões de crédito. Especialmente para pequenos empréstimos, os processos judiciais são evitados o máximo possível, devido à incerteza, às despesas e à natureza demorada dos processos judiciais. Em vez disso, depende-se da cobrança extrajudicial por meio de empresas de cobranças, apesar das vantagens fiscais no procedimento através do sistema judicial. 
A mesma pesquisa aponta que os magistrados concordam com os empresários no que diz respeito aos prejuízos causados ao desenvolvimento econômico pela morosidade e pelos altos custos para acesso ao Judiciário, mas divergem quanto à imparcialidade, defendendo a sua atuação na busca da justiça social na análise de cada caso concreto. E não parece mesmo haver parcialidade quando o juiz julga buscando fazer justiça social em um país onde a Constituição Federal prevê e se compromete com direitos das minorias ${ }^{17}$ (PEREIRA, 2010, p. 75).

Se há concordância entre empresários e magistrados quanto aos problemas envolvendo com altos custos e morosidade, os pleitos dos empresários e as recomendações do Banco Mundial não podem ser considerados equivocados (não, pelo menos por completo, embora precisem ser analisadas com ressalvas, para proteção da soberania nacional). Segundo Frederico Thales de Araújo Martos e José Antonio de Farias Martos, apesar de existir nas recomendações do Banco Mundial para reformas constitucionais (como o documento técnico $\mathrm{n}^{\mathbf{o}} 319$ já mencionado) que atingem os poderes institucionais (como ocorreu com o Poder Judiciário através da Emenda Constitucional no 45, de 30 de dezembro de 2004), "As diretrizes do Banco Mundial demonstram uma preocupação de adequar o Poder Judiciário às necessidades mercadológicas, cujo propósito é de assegurar o crescimento econômico, garantindo a propriedade privada e a estabilidade dos contratos" (s.d., p. 15).

As deficiências do Poder Judiciário no Brasil também foram constatadas através do estudo feito por Silvane Battaglin Schwengber, que fez um extenso trabalho de mensuração de eficiência em diversos tribunais do país ${ }^{18}$, que resultou na sua tese de doutorado. $O$ trabalho acabou concluindo, principalmente, que faltam dados para estudos comparativos (inexistentes ou insuficientes) entre os diversos órgãos do Judiciário. "Os índices de eficiência podem e devem ser mais cuidadosamente analisados se estão refletindo genuína ineficiência técnica ou se refletem outros fatores que, por falta de dados, ainda não puderam ser considerados" (2006, p. 146).

E continua sua conclusão afirmando que "De posse desses indicadores de produtividade as administrações das Comarcas e dos Tribunais podem mais facilmente encontrar as causas dos gargalos do Sistema Judiciário. Torna-se possível começar a distinguir o atraso que é devido às dificuldades da legislação em vigor do atraso que se verifica por razões administrativas ou outras" (2006, p. 146).

Como se vê, uma tentativa de trabalho com profundidade para mensuração dos índices de eficiência sem sequer pôde ser concluída. Outro estudo, de menor complexidade, mas não menos importante, foi desenvolvido pela Secretaria da Reforma do Judiciário, do Ministério da Justiça, e apresentado por Aline Pinheiro, repórter da Revista Consultor Jurídico (CONJUR), exclusivamente sobre as dificuldades de acessar o Judiciário para recebimento de créditos. A título de exemplo, o estudo conclui que se uma determinada pessoa tiver $\mathrm{R} \$ 500,00$ para receber a acionar a Justiça com a finalidade de fazer valer o seu direito, ao final de oito anos (prazo médio para a solução de uma ação desse tipo no Judiciário Brasileiro), terá gasto outros $\mathrm{R} \$ 500,00$ ou mais com custas e despesas processuais e honorários advocatícios. Os titulares de crédito maior ou que dispõem de estrutura jurídica permanente têm mais probabilidades de recebimento, mas os custos chegam a $76 \%$ do valor devido (para crédito de $\mathrm{R} \$ 50.000,00)^{19}$. O estudo conclui, da mesma forma que os já mencionados anteriormente, que a dificuldade de receber o crédito "[...] afeta diretamente a economia brasileira, afasta investidores e eleva a taxa de juros". Foram detectados outros

\footnotetext{
${ }^{17}$ Embora seja possível a investigação - objeto de outro estudo - dos limites dessa atuação buscando justiça social, tais como o ativismo judicial.

${ }^{18}$ Os dados não são apresentados aqui em razão dos limites desse trabalho científico (artigo), mas estão disponíveis para acesso na rede mundiais de computadores.

19 Disponível em: https://www.conjur.com.br/2005-dez-02/estudo_mostra_impacto_acao_judiciario_economia. Acesso em: 14 jun. 2019.
} 
problemas do Judiciário, tal como a alta de congestionamento de processos, em torno de $60 \%$ à época da pesquisa (PINHEIRO, 2005, s.p.).

Os estudos trazidos ao presente trabalho demonstram de forma suficiente que, infelizmente, se o Judiciário Brasileiro deveria ser o ambiente para as correções das imperfeições de mercado, acabou ele próprio se tornando uma falha de mercado ${ }^{20}$. Torna-se, assim, impossível prever, para o cálculo empresarial, resultados decorrentes de ações no Judiciário. Tornou-se mais um item do que R. H. Coase denominou de custos de transação, e que, no Brasil, os economistas passaram a chamar de custo Brasil ${ }^{21}$.

\section{CONSIDERAÇÕES FINAIS}

A análise dos negócios empresariais apenas pela ótica dos conceitos jurídicos não leva em consideração os custos de transação, presentes sempre, das mais variadas formas. A burocracia no Brasil, por exemplo, é um custo de transação a ser levado em consideração. E os empresários, quando se lançam aos negócios, terão que dar importância a esses custos de transação.

Se mercados são imperfeitos, qualquer negócio bem planejado terá que lançar mão de meios para reduzir os custos de transação. Se o arcabouço jurídico não permite, atualmente, que no âmbito das relações privadas as partes contratantes encontrem a solução para os custos de transação, as empresas devem buscar nas normas jurídicas - atualmente bastante influenciadas por estudos econômicos - o equilíbrio para os negócios e para o mercado.

$\mathrm{O}$ acesso a um Judiciário eficiente passa a ser um componente fundamental no planejamento do negócio, para que possa obter o empresário, quando necessário, o cumprimento da legislação e dos contratos, de forma que componham os resultados de acordo com o planejamento.

Se o sistema jurisdicional brasileiro, segundo os dados disponíveis e segundo os relatos dos próprios magistrados, tem altos graus de ineficiência e não presta o serviço jurisdicional de forma adequada, no prazo e na forma desejada, não funcionará como elemento de correção às imperfeições de mercado e, pior, passará a ser mais um problema a ser dimensionado pelos empresários.

A constatação de que o próprio Judiciário se tornou uma falha de mercado é péssima para a economia brasileira e é um dos indicadores que demonstram que temos muito a evoluir. Os investidores e empresários têm que pensar nos seus negócios apesar do Judiciário, quando, na verdade, deveriam contar com o apoio do sistema jurídico.

A insegurança jurídica é um desestímulo ao investimento, aos novos negócios, e o Judiciário, que deveria corrigir as distorções de mercado, é mais um complicador nesse emaranhado de situações que prejudicam as atividades empresariais no Brasil. Não é sem razão que está o país com a economia estagnada há bastante tempo, porque o ambiente é extremamente desestimulante para os novos negócios e para manutenção dos já existentes. Se o mau

\footnotetext{
${ }^{20}$ E nem se diga que os meios alternativos de solução de controvérsias poderiam ser caminhos mais eficientes para o problema. O assunto comporta outro estudo, mas é sabido que os resultados, em termos de efetividade, são pífios. Além disso, o principal deles, a arbitragem, diante dos altos custos, é acessível apenas para pessoas de renda alta e empresas de grande porte.

${ }^{21}$ Denominação genérica dada a uma série de custos de produção, ou despesas incidentes sobre a produção, que tornam difícil ou desvantajoso para o exportador brasileiro colocar seus produtos no mercado internacional, ou então tornam inviável ao produtor nacional competir com os produtos importados. Tais custos estariam relacionados com aspectos legais (legislação trabalhista, por exemplo, e os encargos sociais), institucionais (excesso de burocracia para a instalação de empresas ou para a exportação de produtos), tributários (excesso de tributos sobre produtos que direta ou indiretamente participam das exportações ou sofrem concorrência de produtos estrangeiros), de infra-estrutura (falta de estradas bem conservadas, comunicações deficientes e caras) e corporativas (domínio de sindicatos de trabalhadores sobre certos tipos de atividade, dificultando a incorporação de progresso técnico e o aumento da produtividade (SANDRONI, 1999).
} 
funcionamento do Judiciário não pode ser apontado como a única causa, certamente tem grande parcela dessa responsabilidade.

\section{REFERÊNCIAS}

BRASIL. Emenda Constitucional $n^{\circ} 45$. Altera dispositivos dos arts. 5o , 36, 52, 92, 93, 95, 98, 99, 102, 103, 104, 105, 107, 109, 111, 112, 114, 115, 125, 126, 127, 128, 129, 134 e 168 da Constituição Federal, e acrescenta os arts. 103-A, 103B, 111-A e 130-A, e dá outras providências. Disponível em:

http://www.planalto.gov.br/ccivil_03/constituicao/emendas/emc/emc45.htm. Acesso em: 15 jul. 2019.

CALABRESI, Guido. Some Thoughts on Risk Distributions and de Law of Torts. Yale Law School. Yale Law School Legal Scholarship Repository. 1961. Disponível em: https://digitalcommons.law.yale.edu/cgi/viewcontent.cgi article=3035\&context=fss_papers. Acesso em: 23 mai. 2019.

CALABRESI, Guido; BOBBITT, Philip. Tragic Choices: the conflicts society confronts in the allocation of tragically scarce resources. New York: Norton \& Company, 1978.

COASE, Ronald Harry. A firma, o mercado e o direito. Tradução: Heloisa Gonçalves Barbosa, Revisão técnica: Alexandre Veronese, Lucia Helena Salgado e Antonio José Maristrello Porto. Revisão final: Otavio Luiz Rodrigues Junior. Rio de Janeiro: Forense Universitária, 2016 (Coleção Paulo Bonavides).

COASE, Ronald Harry. The Problem of Social Cost. The University Of Chicago. The Journal of Law \& Economics. Disponível em: https://www.law.uchicago.edu/files/file/coase-problem.pdf. Acesso em: 23 mai. 2019.

COASE, Ronald Harry. The Federal Communications Commission. The University Of Chicago. The Journal of Law \& Economics. Disponível em: https://www.journals.uchicago.edu/doi/10.1086/466549?mobileUi=0. Acesso em: 24 jun. 2019.

COELHO, Fábio Ulhoa. Curso de Direito Comercial. Direito de empresa, v. 1. 17. ed. São Paulo: Ed. Saraiva, 2013.

CONSTANTINO, Rodrigo. O Custo Social: a contribuição de Ronald Coase aos estudos econômicos. Gazeta do Povo. 12 jan. 2015. Disponível em:

https://www.gazetadopovo.com.br/rodrigo-constantino/artigos/o-custo-social-a-contribuicao-deronald-coase-aos-estudos-economicos/. Acesso em: 31 mai. 2019.

COULON, Fabiano Koff. Critérios de quantificação dos danos extrapatrimoniais dotados pelos Tribunais Brasileiros e Análise Econômica do Direito. In: TIMM, Luciano Benetti (org.). Direito \& Economia. 2. ed. Porto Alegre: Livraria do Advogado Editora, 2008.

DAKOLIAS, Maria. O setor Judiciário na América Latina e no Caribe. Tradução: Sandro Eduardo Sardá. Banco Mundial. Documento Eletrônico número 319. Elementos para Reforma. Washington, DC. Disponível em: https://www.anamatra.org.br/attachments/article/24400/00003439.pdf. Acesso em: 22 jul. 2019. 
FALCÃO, Raimundo Bezerra. Direito Econômico. Teoria Fundamental. São Paulo: Malheiros Editores, 2013.

FERREIRA, Antonio Carlos; FERREIRA, Patrícia Cândido Alves. Estudo Introdutório para a edição brasileira de A Firma, o mercado e o Direito. In: COASE, Ronald Harry. A firma, o mercado e o direito. Tradução: Heloisa Gonçalves Barbosa, Revisão técnica: Alexandre Veronese, Lucia Helena Salgado e Antonio José Maristrello Porto. Revisão final: Otavio Luiz Rodrigues Junior. Rio de Janeiro: Forense Universitária, 2016 (Coleção Paulo Bonavides).

FONTOURA, Fernando Batista Bandeira da. Gestão de Custos: uma visão integradora e prática dos métodos de custeio. São Paulo: Ed Atlas, 2013.

FREZATTI, Fábio. Orçamento Empresarial: planejamento e controle gerencial. 5. ed. São Paulo: Ed. Atlas, 2009.

IUDÍCIBUS, Sérgio de. Contabilidade Gerencial. 6. ed. São Paulo: Ed. Atlas, 1998.

JAKOBI, Karin Bergit; RIBEIRO, Marcia Carla Pereira. A Análise Econômica do Direito e a regulação do Mercado de Capitais. E-book. São Paulo: Ed. Atlas, 2014.

LAZARI, Rafael José Nadim de. Reserva do possível e mínimo existencial: a pretensão de eficácia da norma constitucional em face da realidade. Curitiba: Juruá, 2012.

MACKAAY, Ejan; ROUSSEAU, Stéphane. Tradução: Rachel Sztajn. Análise Econômica do Direito. E-book. 2. ed. São Paulo: Ed. Atlas, 2015.

MARTOS, Frederico Thales de Araújo; MARTOS, José Antonio de Faria. A Influência Mundial na Reforma do Poder Judiciário e no Acesso à Justiça no Brasil. Disponível em: http://www.publicadireito.com.br/artigos/?cod=1e00996d70a49ff8. Acesso em: 15 jul. 2019.

MATSUMI, Tayuri Ishi; PEREIRA, Carmem Letícia da Maia. Heurísticas e vieses no processo decisório do juiz. In: PEREIRA, Carmem Letícia da Maia; CUNHA, Mariana Forbeck; POZZOBON, Thayse Cristine (org.). A Análise Econômica do Direito e as relações jurídicas atuais: aspectos e reflexões. Curitiba: Editora CRV, 2017.

NOBEL PRIZE ORG. Ronald H. Coase. Disponível em: https://www.nobelprize.org/prizes/economic-sciences/1991/summary/. Acesso em: 24 jul. 2019.

NUSDEO, Fábio. Fundamentos para uma Codificação do Direito Econômico. São Paulo: Ed. Revista dos Tribunais, 1995.

PACHECO, Pedro Mercado. El Analisis Economico del Derecho: una Reconstruccion Teorica. Madrid: Centro de Estudios Constitucionales, 1994.

PEÑALOZA, Rodrigo. Externalidades e o Teorema de Coase. Medium.com. Disponível em: https://medium.com/@milesmithrae/externalidades-e-o-teorema-de-coase-rodrigope\%C3\%B1aloza-dez-2015-6ebb29f90120. Acesso em: 31 mai. 2019.

PEREIRA, Micheli. O mau funcionamento do Poder Judiciário como empecilho ao desenvolvimento econômico brasileiro. In: Constituição, Economia e Desenvolvimento: Revista 
da Academia Brasileira de Direito Constitucional, vol. 2, n. 2. Curitiba, jan-jun/2010. p. 52-85. Disponível em: http://www.abdconst.com.br/revista2/mauMicheli.pdf. Acesso em: 13 ago. 2020.

PINHEIRO, Aline. Estudo mostra impacto da ação do Judiciário na economia. In: Consultor Jurídico (CONJUR). Revista Eletrônica. 2 dez. 2005. Disponível em:

https://www.conjur.com.br/2005-dez-02/estudo_mostra_impacto_acao_judiciario_economia. Acesso em: 14 jun. 2019.

SANDRONI, Paulo (org. e sup.). Novíssimo dicionário de Economia. São Paulo: Editora Best Seller, 1999.

SARTORI, Marcelo Vanzella. As falhas de mercado diante da Análise Econômica do Direito ambiental e do patrimônio cultural como bens coletivos. In: Revista Universitas. Ano 2 - n. 2. Mogi Mirim/SP, jan-jun/2009.

SCHWENGBER, Silvane Battaglin. Mensurando a eficiência no sistema judiciário: métodos paramétricos e não-paramétricos. Tese (Doutorado em Economia) - Universidade de Brasília. 2006. Disponível em:

https://repositorio.unb.br/bitstream/10482/3190/1/tese\%20Silvane\%20Battaglin\%20Schwengber. pdf. Acesso em: 13 ago. 2020.

SLAIBI FILHO, Nagib. Magistratura e gestão judiciária. E-book. Rio de Janeiro: Forense, 2016.

SZTAJN, Rachel. Teoria Jurídica da Empresa: atividade empresária e mercados. E-book. 2. ed. São Paulo: Ed. Atlas, 2010.

TRINDADE, Manoel Gustavo Neubarth. Direito contratual como redutor das falhas de mercado. Dissertação (Mestrado pelo Programa de Pós-Graduação da Faculdade de Direito). Universidade Federal do Rio Grande do Sul. Porto Alegre, 2013. Disponível em: https://lume.ufrgs.br/handle/10183/77180. Acesso em: 15 jul. 2019. xto. 